\title{
Long-term effects of childhood speech and language disorders: A scoping review
}

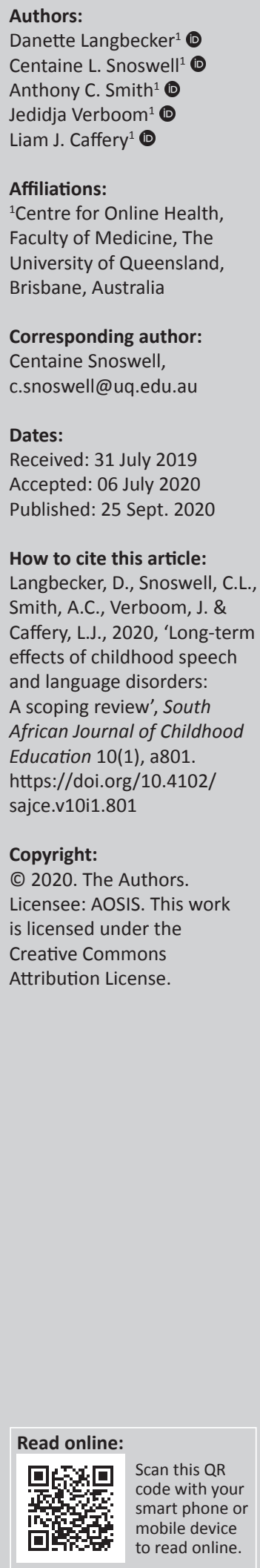

Background: Speech and language disorders in childhood have the potential to affect every aspect of a child's day-to-day life and can potentially have negative long-term impacts.

Aim: This scoping review seeks to collate the existing evidence to identify the long-term effects of childhood speech and language disorders.

Methods: A systematic search of speechBITE, ERIC (Education Resources Information Center), Linguistics and Language Behaviour Abstracts, PubMed, MEDLINE, PsycINFO, SocINDEX and the Cochrane Library was conducted. Peer-reviewed English language publications reporting on the long-term (2+-year) outcomes of individuals with a childhood history of speech or language disorders were included. Data were extracted and the study quality assessed using a modified Newcastle-Ottawa scale.

Results: Fifty-one studies met the inclusion criteria. These studies reported mixed results, the most common of which were suboptimal mental health, social and academic outcomes for persons with a history of speech or language disorders. We found an association between childhood speech or language disorders and psychiatric disability, behavioural problems, lower socio-economic status, relationship and living difficulties, and lower academic achievement compared to the general population.

Conclusion: Individuals with a history of childhood speech or language disorders may experience long-term difficulties in mental health, social well-being and academic outcomes.

Keywords: speech and language; mental health; behaviour; psychosocial; quality of life; scoping review.

\section{Introduction}

Speech and language disorders (SLDs) in childhood are a public health concern. Childhood SLDs are associated with effects on the day-to-day lives of individuals and can potentially have negative long-term personal development and opportunity effects (Arkkila et al. 2009; Beitchman, Brownlie \& Bao 2014; Clegg 2006). Speech and language disorder communication difficulties can limit an individual's ability to participate in society and may lead to reduced social and emotional well-being. Speech and language disorders often result in economic effects for the individual and society (Community Affairs References Committee \& Siewert 2014). The societal economic burden may be substantial if the individual progresses to criminal behaviours, needs increased mental health services, is unemployed and requires ongoing support, or needs support from adult literacy programmes (Gross 2006). Additionally, a disproportionate number of SLDs are experienced by socio-economically disadvantaged populations, which often means that economic barriers inhibit access to appropriate assistance services (Law et al. 2017; Maggi et al. 2010).

Internationally, the reporting of SLD prevalence varies. This variation is likely a result of the differences in identification methods, reporting requirements and diagnostic criteria between countries. In the United States (US), it has been reported that $8 \%$ of children aged 3-17 years have voice, speech, language or swallowing disorders (Black, Vahratian \& Hoffman 2015). In the United Kingdom (UK), 6\% of children are reported to have speech and language delays (Law et al. 2000), which is similar to the estimated $6 \%-9 \%$ of children in South Africa (Nwosu 2015; Pascoe, Mahura \& Le Roux 2018). In Australia, the prevalence of communication impairments ranges from $<1 \%$ to $21 \%$ amongst Australian children, depending on the reference source, with prevalence highest amongst younger children (McCormack et al. 2007). 
To facilitate evidence-based intervention selection and conduct economic evaluations for these treatment options, an overview of the long-term outcomes from SLDs is first required. This review examines the long-term outcomes for individuals who have experienced childhood SLDs. The existing evidence focuses on singular outcome effects resulting from childhood SLDs (Baltaxe \& Simmons 1975; Jackson et al. 2009; Kent \& Vorperian 2013); this review aims to provide a concise overview of all of the potential long-term effects of having a childhood SLD. The results of this research can provide patients, carers and health professionals with an overview of the current evidence, an essential tool in the era of evidence-based practice (EBP). To gain a holistic picture of the impact of SLDs, all relevant information needs to be examined; this requires the inclusion of many studies that examine SLDs without differentiating between SLDs. Separating the two would likely exclude valuable studies conducted before the two terms were independently defined. This scoping review seeks to answer the question: what are the potential long-term effects of childhood SLDs that have been reported in the literature? To do this, it identifies and analyses the existing evidence base and provides an overview of the long-term impact of SLDs, to provide solid evidence to guide future research, influence public policy and guide clinical practice.

\section{Methods}

This scoping review followed the methods outlined by Levac, Colquhoun and O'Brien (2010), comprising five main stages: (1) identify the research question; (2) identify relevant studies; (3) select studies; (4) chart the data; and (5) collate, summarise and report the results. A scoping review is a method for mapping areas of research and presenting the results in an accessible format for knowledge users (Grudniewicz et al. 2016).

\section{Identification of relevant studies}

\section{Search criteria}

In 2017, speechBITE, ERIC, Linguistics and Language Behaviour Abstracts, PubMed, MEDLINE, PsycINFO, SocINDEX and the Cochrane Library were searched. The aim was to identify studies investigating the impact of childhood SLDs or SLD therapy on individual and social aspects during adolescence and adulthood. As there is variation in the historical and international reporting of SLDs, we have not separated speech disorders and language disorders for this scoping review, as is now current practice. The search strategy included the following terms:

- speech or language or language development or language disorders or communication disorders

- impairment or problem or difficult* or pathology or disorder

- long-term or follow-up

- psychology or psychosocial or behavio*r or mental health or emotional health.

The terms were adapted as necessary for each database. As there were no previous reviews on the topic, the searches were not time constrained. The final searches were conducted in August 2017. Reference lists of the included studies were searched for additional citations.

\section{Selection criteria}

We included only studies that reported primary data and were peer-reviewed academic journal items, PhD dissertations, research reports or full conference papers. Articles were excluded if they were not available in English, did not pertain to humans, specifically examined SLDs resulting from either biomedical conditions such as Down syndrome or neurogenic, neuromotor or neurosensory impairments such as aphasia (Efstratiadou et al. 2018).

\section{Study selection}

Titles and abstracts were screened by one researcher (J.V.) against the selection criteria and categorised for inclusion or exclusion. In case of uncertainty, a second researcher (D.L.) screened the title and abstract against the selection criteria. Disagreements were resolved by consensus or consultation with a third researcher (L.J.C. or A.C.S.).

After the review of titles and abstracts, full-text review of the articles was conducted according to criteria. Mental health, social well-being and academic outcomes were defined as the three main outcomes. Studies were excluded when they did not report mental health, social or academic outcomes, had less than 2 years of follow-up, described self-reported SLDs or participants with an intelligence quotient (IQ) of $<80$ (to rule out general intellectual disability). In the absence of clinical information that could guide the choice of follow-up period, 2 years was chosen to ensure that study follow-ups occurred after initial assessments, whilst also including as many relevant studies as possible. Studies were not excluded if they presented different results from the same data set. No limitations were placed on participant age at enrolment or for followup for the included studies.

\section{Data extraction}

The full text of articles that met the inclusion criteria was read, and data were extracted by one researcher (J.V.) using an abstraction form. Based on the recommendations of Levac et al. (2010), the data abstraction form was collectively and iteratively developed as the scope of the review was clarified. The data abstraction form was pilot-tested by two researchers (J.V. and D.L.) for five articles to ensure consistency and to test the form. The data extracted included the publication details, study design and aim, sample, years of follow-up, type of impairment, age at onset, specific outcomes reported and results on relevant outcomes.

\section{Quality assessment}

The quality of included studies was assessed to provide an understanding of the strength of evidence of each study and to inform the interpretation of the review conclusions. A modified Newcastle-Ottawa scale was used 
to determine a quality rating for each study (Wells et al. 2000). This scale assesses the quality of non-randomised studies by allocating a score based on study group selection, group comparability and the method by which the exposure or outcome of interest is ascertained (Wells et al. 2000). The scale was also modified to remove a criterion not relevant to this review and to score one criterion using two rather than three points. The modified scale and its coding are shown in the Appendix 1. The quality was rated independently by two researchers (J.V. and D.L./ L.J.C.) in an iterative manner, with a discussion of any discrepancies to reach consensus with adjudication from a third member of the research team (A.C.S.). Studies were categorised as a higher or lower quality based on their overall quality rating $(\mathrm{QR})$ using a median split (6+ vs. $<6$, respectively, on the $0-8$ scale). Studies were not excluded based on quality rating.

\section{Data analysis and synthesis}

The study results were broadly categorised into mental health, social well-being and academic outcomes. Some outcomes such as loneliness (measured in relation to quality of life) could be categorised under multiple categories such as mental health or social well-being. Classification of subcategories was determined by consensus between researchers (J.V. and D.L.) and is shown in Figure 1. The results are presented to show an overall coherent picture of the included studies, considering their quality rating and results, including null findings. Synthesis of the findings was performed narratively.

The term 'speech and language disorder' (SLD) as opposed to 'impairment' is used in this review. However, for consistency and accuracy throughout this article, the terminology used by the authors has been preserved where possible.

\section{Review findings}

A total of 51 articles were included in the review. The results of the search and screening stages are shown in the PRISMA (Preferred Reporting Items for Systematic Reviews and Meta-Analyses) flow chart (see Figure 2).

\section{Study characteristics}

All included studies used a cohort design and were largely $(n=36)$ published after the year 2000 (Table 1). Studies were predominantly conducted in the UK $(n=21)$, US $(n=10)$ and Canada $(n=9)$, on 27 unique cohorts. Most studies reported more than one outcome measure. In total 84 unique outcomes were reported across the 51 studies (Figure 1 and Table 2); 40 studies reported mental health outcomes, 27 reported social well-being outcomes, and 17 reported academic outcomes (Table 2). The age of participants at follow-up (7-39 years) and the length of follow-up (4-31 years) varied considerably. The quality rating of the reviewed studies ranged from 3 to 8 with a median of 6 , out of a possible total of 8 . Specific language impairments (SLIs) and developmental language disorders (DLDs) were the most common diagnoses reported within the studies (determined by use of this specific terminology).

\section{Mental health outcomes}

Four studies reported positive associations between childhood SLD and poor mental health (not otherwise specified) (Arkkila et al. 2009; Clegg et al. 2005; Law et al.

\begin{tabular}{|c|c|c|c|}
\hline \multicolumn{4}{|c|}{ Mental health outcomes } \\
\hline \multicolumn{2}{|l|}{$\begin{array}{l}\text { Psychiatric disorders } \\
\text { Mood disorders (depression, anxiety disorder) } \\
\text { Personality disorders }\end{array}$} & \multicolumn{2}{|l|}{$\begin{array}{l}\text { Substance use disorders } \\
\text { Illicit drug \& alcohol misuse/abuse }\end{array}$} \\
\hline \multicolumn{2}{|l|}{$\begin{array}{l}\text { Behavioural problems } \\
\text { Behavioural disturbances (hyperactivity, social withdrawal) } \\
\text { Behavioural difficulties/problems/delinquent behaviours } \\
\text { Reactive temperaments/emotional problems } \\
\text { Prosocial behaviour }\end{array}$} & \multicolumn{2}{|l|}{$\begin{array}{l}\text { Quality of life } \\
\text { Quality of life (health related or other) } \\
\text { Personal happiness } \\
\text { Life satisfaction } \\
\text { Vitality }\end{array}$} \\
\hline \multicolumn{3}{|c|}{ Social well-being outcomes } & \multirow{3}{*}{$\begin{array}{l}\qquad \text { Academic outcomes } \\
\text { Academic/educational achievement/grades } \\
\text { Satisfaction with academic results } \\
\text { Completion of educational programs } \\
\text { Pursue further education } \\
\text { Need for special education support }\end{array}$} \\
\hline $\begin{array}{l}\text { Social behaviour } \\
\text { Social cognition/performance/problems } \\
\text { Shyness } \\
\text { Participation in social activities }\end{array}$ & $\begin{array}{l}\text { Independent living } \\
\text { Independency } \\
\text { Living with parents }\end{array}$ & & \\
\hline $\begin{array}{l}\text { Employment } \\
\text { Employment rates } \\
\text { Skilled jobs/SES for occupation } \\
\text { Full/part time employment } \\
\text { Work difficulties }\end{array}$ & \multicolumn{2}{|c|}{$\begin{array}{l}\text { Relationships } \\
\text { Friendship number \& quality } \\
\text { Peer scores/problems/bullying } \\
\text { Romantic relationship } \\
\text { Sexual assault }\end{array}$} & \\
\hline
\end{tabular}

SES, socio-economic status.

FIGURE 1: Classification of mental health, social well-being and academic outcomes. 
TABLE 1: Study characteristics $(n=51)$.

\begin{tabular}{|c|c|}
\hline Characteristic & $n$ \\
\hline \multicolumn{2}{|l|}{ Publication year } \\
\hline 1971-1980 & 1 \\
\hline 1981-1990 & 5 \\
\hline 1991-2000 & 9 \\
\hline 2001-2010 & 24 \\
\hline 2011-2017 & 12 \\
\hline \multicolumn{2}{|l|}{ Sample } \\
\hline \multicolumn{2}{|l|}{ Community sample } \\
\hline Ottawa-Carleton sample & 9 \\
\hline Bishop-Edmundson sample & 2 \\
\hline Other & 8 \\
\hline Clinical sample & 7 \\
\hline \multicolumn{2}{|l|}{ Birth cohort sample } \\
\hline 1970 UK birth cohort & 3 \\
\hline Danish children with language disorder & 3 \\
\hline Other & 3 \\
\hline \multicolumn{2}{|l|}{ School sample } \\
\hline Conti-Ramsden Manchester language study & 10 \\
\hline Templin investigation in kindergarten & 2 \\
\hline Other & 4 \\
\hline \multicolumn{2}{|l|}{ Years of follow-up } \\
\hline$<10$ years & 24 \\
\hline$\geq 10$ years & 27 \\
\hline \multicolumn{2}{|l|}{ Quality assessment rating $\dagger$} \\
\hline Median (range) & $6(3-8)$ \\
\hline \multicolumn{2}{|l|}{ Country of publication } \\
\hline United Kingdom & 21 \\
\hline United States & 10 \\
\hline Canada & 9 \\
\hline Denmark & 4 \\
\hline Other & 7 \\
\hline \multicolumn{2}{|l|}{ Type of disorder studied } \\
\hline DLD (4)/SLI (20) & 24 \\
\hline Speech and language disorder & 12 \\
\hline Specific (receptive) language disorder & 5 \\
\hline Early language development & 4 \\
\hline Language disorder & 2 \\
\hline Speech disorder & 2 \\
\hline Developmental language delay & 1 \\
\hline Late talking & 1 \\
\hline \multicolumn{2}{|l|}{ Age at outcome } \\
\hline Childhood, 7-9 years & 3 \\
\hline Early adolescence, $10-14$ years & 6 \\
\hline Adolescence, $15-19$ years & 22 \\
\hline Early adulthood, $20-29$ years & 7 \\
\hline Adulthood, $30-39$ years & 12 \\
\hline Mixed sample & 1 \\
\hline \multicolumn{2}{|l|}{ Studies reporting outcomes } \\
\hline Mental health & 40 \\
\hline Social well-being & 27 \\
\hline Academic outcomes & 17 \\
\hline
\end{tabular}

DLD, developmental language disorder; SLI, specific language impairment; UK, United Kingdom.

$\dagger$, Scores range low to high, $0-8$

2009; Schoon et al. 2010). Further outcomes relating to mental health were categorised into four areas: (1) psychiatric disorders, (2) behavioural problems, (3) substance use disorders and (4) quality of life.

\section{Psychiatric disorders}

Amongst the eight studies examining overall psychiatric disorders (including mood disorders or personality disorders), two reported no association (Howlin et al. 2000; Snowling et al. 2006) and six reported an association with childhood SLD (Baker \& Cantwell 1987; Beitchman et al. 1996a, 1996b, 1999, 2001a; Whitehouse et al. 2009). Other studies examined psychiatric conditions individually (Table 1). When the subset of mood disorders (i.e. depression, bipolar disorder, anxiety disorder) was examined, two studies with comparable quality ratings reported disparate results. One reported an increased risk of mood disorders amongst participants with deteriorated vocabulary performance over follow-up (Armstrong et al. 2017), while the other reported no difference between SLD participants and their controls (Beitchman et al. 2014). In contrast, for the subset of personality disorders (long-term, extreme and inflexible patterns of thinking, behaviour and emotion), all three studies found more personality disorders in SLD participants than controls, and all three studies received high-quality ratings (Beitchman et al. 1999, 2001, Mouridsen \& Hauschild 2009b). Eight out of 11 studies examining anxiety reported an association with childhood SLD. Three of these studies were led by Beitchman et al.; two reported higher anxiety problems in their cohort at age 19 years (Beitchman et al. 1999, 2001), while the third reported no difference at age 31 years (Beitchman et al. 2014). The difference could not be explained by dropout or change in language abilities over time. Beitchman et al. proposed that this may be a result of the demanding environment experienced by participants at 19 years of age resulting from their developmental stage, potential academic difficulties and SLD challenges (Beitchman et al. 2014).

There was mixed evidence that childhood SLD was associated with depression (Conti-Ramsden \& Botting 2008b; Durkin, Conti-Ramsden \& Simkin 2012; Lewis et al. 2016; Schoon et al. 2010; Wadman et al. 2011a). Of the five studies with similar quality ratings, three reported more depression in SLD participants than controls, whereas the other two studies reported no difference. Similarly, Lindsay et al. found that persons with a history of SLDs had lower self-esteem than their controls at age 16, but found no difference at age 17 (Lindsay, Dockrelll \& Palikara 2010).

\section{Behavioural problems}

Of the 15 studies that examined behavioural difficulties, 11 studies found a strong association between childhood SLD and behavioural difficulties. Baker and Cantwell (1987) and Yew and O'Kearney (2015) reported more hyperactive behaviour and reactive temperaments amongst participants with a history of SLDs. Similarly, Benasich, Curtiss and Tallal (1993) reported overall behavioural disturbances - hyperactivity in both male and female participants and social withdrawal in female participants. 


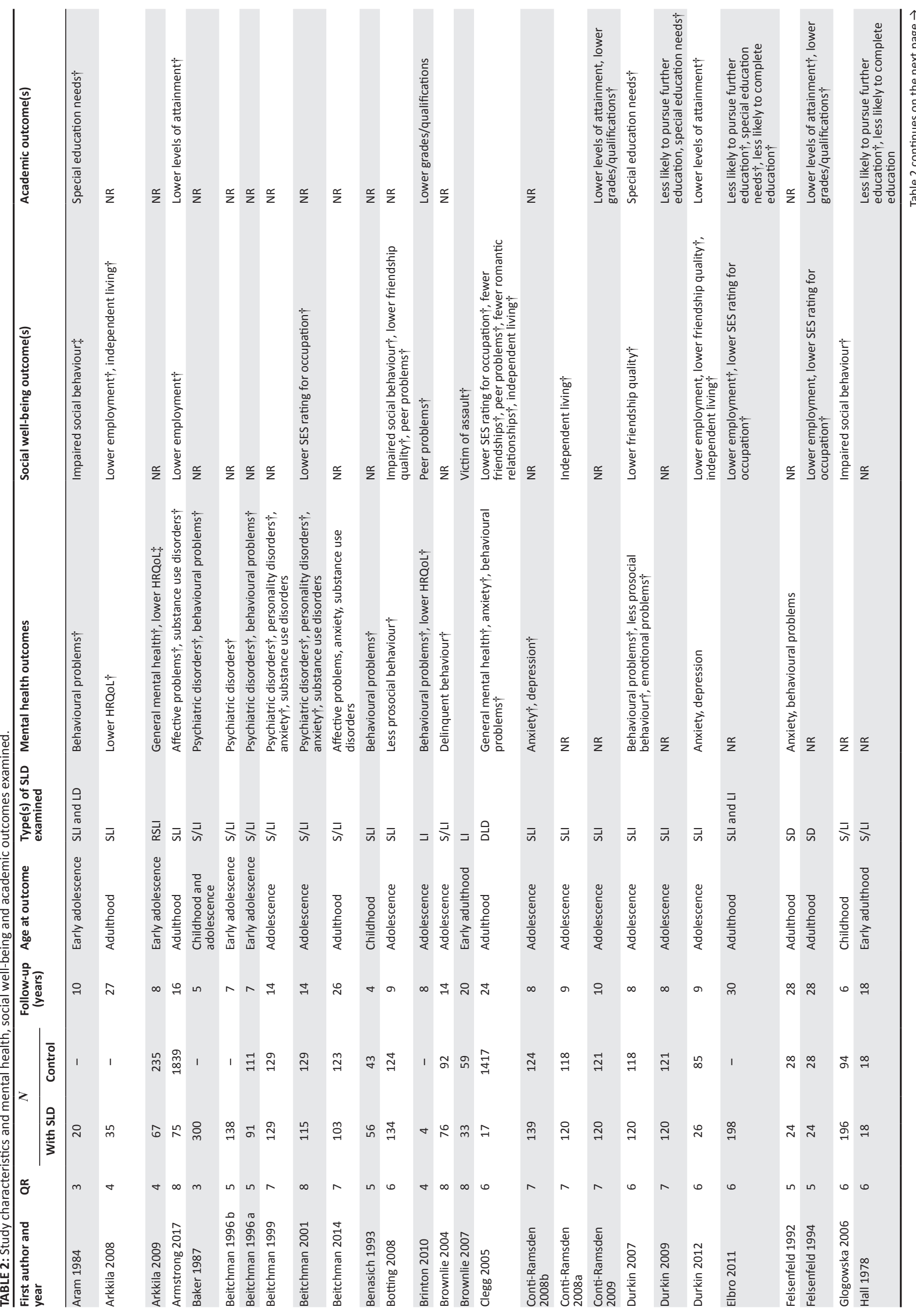




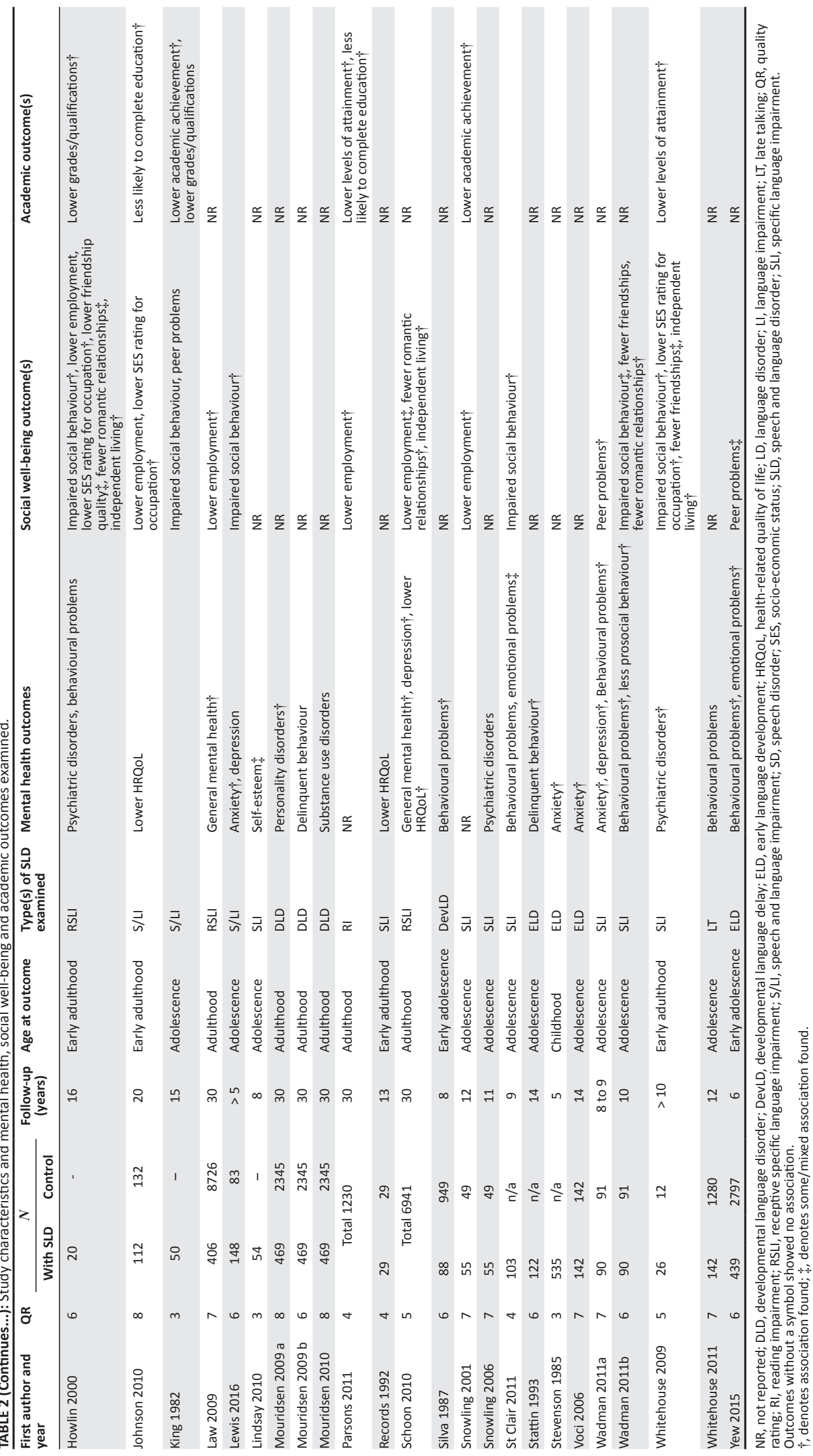




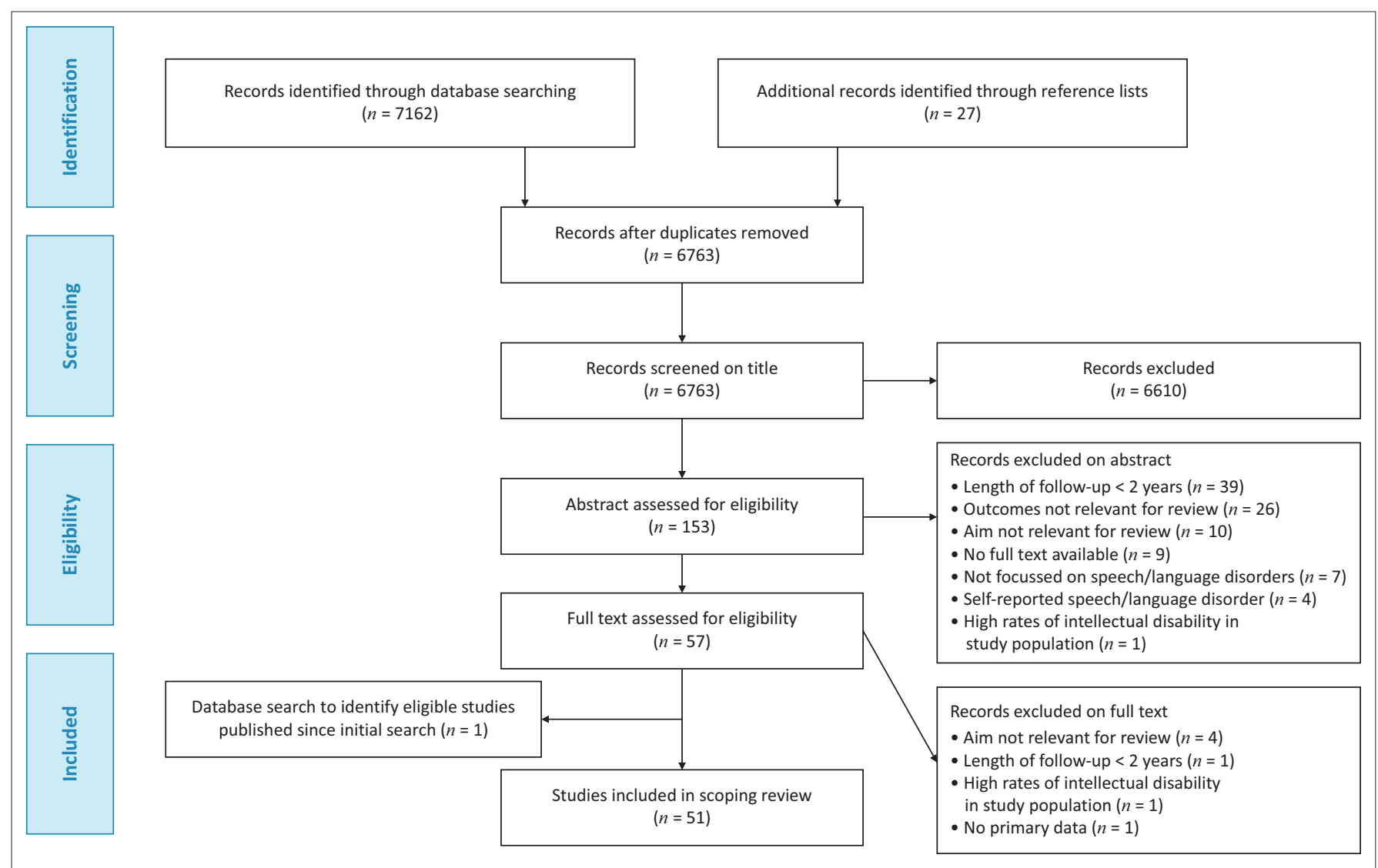

PRISMA, Preferred Reporting Items for Systematic Reviews and Meta-Analyses.

FIGURE 2: PRISMA flow chart showing study selection.

Other studies showed overall difficulties in behaviour; studies that examined prosocial behaviour (empathic behaviour intended to help others with no expectation of reward) reported difficulties with this behaviour in later life for those with childhood SLDs (Botting \& Conti-Ramsden 2008; Durkin \& Conti-Ramsden 2007; Wadman et al. 2011b). Three studies examined delinquent behaviour; two (Brownlie et al. 2004; Stattin \& Klackenberglarsson 1993) of them showed a strong association with SLDs, whilst the third found no evidence of association (Mouridsen \& Hauschild 2009a). Emotional problems in participants with SLDs were reported by Durkin and Conti-Ramsden (2007), St Clair et al. (2011), Yew and O'Kearney (2015). The results from St Clair et al. also demonstrated a decrease in emotional problems over time; however, their ultimate prevalence in those with childhood SLDs remained higher than in the general population (St Clair et al. 2011). In contrast, four studies reported no association between childhood SLD and behaviour difficulties (Felsenfeld, Broen \& Mcgue 1992; Howlin et al. 2000b; St Clair et al. 2011; Whitehouse, Robinson \& Zubrick 2011).

\section{Substance use disorders}

Substance use disorders were investigated by five studies, with one study reporting that adults with deteriorated vocabulary performance had an increased risk for illicit and alcohol misuse or abuse (Armstrong et al. 2017). However, four other studies found no difference in rates of substance use disorders between persons with a history of SLDs and their controls (Beitchman et al. 2014, 1999, 2001; Mouridsen \& Hauschild 2010).

\section{Health-related quality of life}

Mixed results were reported about health-related quality of life (HRQoL). Studies such as that by Arkkila et al. reported no differences in overall HRQoL; however, the results indicated a lower vitality score for participants with a history of SLD (Arkkila et al. 2009). Three studies showed that SLDs had a great effect on HRQoL (Arkkila et al. 2008), assumedly because individuals with SLDs felt lonely (Brinton, Fujiki \& Baldridge 2010), reported lower satisfaction with life and felt no control over life compared to the control groups (Schoon et al. 2010). In contrast, two studies reported no difference in quality of life (Johnson, Beitchman \& Brownlie 2010), personal happiness or life satisfaction (Records, Tomblin \& Freese 1992) between those with a history of SLDs and control groups.

\section{Social well-being outcomes \\ Social behaviour}

The majority of the studies that examined social behaviour reported lower social behaviour amongst persons with a history of SLDs compared to controls, although three studies found no discernible difference. These findings included 
lower social cognition (Botting \& Conti-Ramsden 2008) and social performance (Aram, Ekelman \& Nation 1984) and significantly higher rates of social problems (Glogowska et al. 2006; Lewis et al. 2016). Dissimilar results were reported by Wadman et al., who found that although persons with a history of specific language impairment (SLI) were more likely to be shy, they had overall similar social behaviours to controls (Wadman et al. 2011b). This result was supported by two studies that reported similar participation in social activities amongst persons with SLD history compared to control groups (Aram et al. 1984, King, Jones \& Lasky 1982), although these studies received lower quality ratings.

\section{Employment}

No consensus was found as to whether childhood SLDs were associated with lower employment rates in later life. It was clear, however, that when employed, the socioeconomic status of persons with a history of SLDs was lower than that of control groups. Several studies showed that persons with a history of SLDs were more likely to be in less-skilled jobs than controls (Clegg et al. 2005; Elbro, Dalby \& Maarbjerg 2011; Felsenfeld, Broen \& Mcgue 1994; Howlin et al. 2000; Parsons et al. 2011; Whitehouse et al. 2009) and less likely to be employed in a full-time job (Arkkila et al. 2008; Armstrong et al. 2017; Beitchman et al. 2001; Snowling et al. 2001). Durkin et al. reported lower part-time employment for participants with a history of an SLD; however, the presence of autism spectrum disorder symptomatology was also found to be a significant predictor of employability in this study (Durkin et al. 2012). Participants with a history of SLDs were reported as unemployed for longer periods than controls in three studies (Clegg et al. 2005; Law et al. 2009; Parsons et al. 2011). Moreover, Clegg et al. and Howlin et al. reported that persons with a history of SLDs had more difficulties in the work environment and that behaviour-related problems were often referenced in reasons for dismissal (Clegg et al. 2005; Howlin et al. 2000). In contrast, other studies reported no substantial difference in employment rates (Felsenfeld et al. 1994; Johnson et al. 2010).

\section{Relationships}

There was no reported difference in the number of friendships for participants with SLDs and controls across studies; however, the overall quality of friendships was rated lower by SLD participants. All but one study (King et al. 1982) reported lower peer scores or more peer problems amongst persons with a history of SLDs compared to controls (Botting \& Conti-Ramsden 2008; Brinton et al. 2010; Wadman et al. 2011b), although Yew et al. suggested that this was only true for girls (Yew \& O'Kearney 2015). Persons with a history of SLDs were reported to experience more instances of bullying (Wadman et al. 2011a), have fewer acquaintances and be more awkward and limited in making contact (Clegg et al. 2005). When romantic relationships were examined, fewer participants with a history of SLDs were in romantic relationships compared to controls (Clegg et al.
2005; Schoon et al. 2010; Wadman et al. 2011b), although no difference was found for participants with a DLD history (Howlin et al. 2000). Additionally, Brownlie et al. (2007) found that language-impaired women were more likely than controls to have experienced sexual assault.

\section{Independent living}

All seven studies that examined independent living reported low independency or higher rates of living with parents for persons with a history of SLDs compared to control groups (Arkkila et al. 2008; Clegg 2006, Conti-Ramsden \& Durkin 2008a; Durkin et al. 2012; Howlin et al. 2000; Schoon et al. 2010; Whitehouse et al. 2009).

\section{Academic outcomes}

Overall, academic achievement was lower for participants with an SLD when compared to controls (Durkin et al. 2012; King et al. 1982; Snowling et al. 2001). This finding was supported by the results of studies that examined specific academic outcomes such as the need for special education support or the likelihood of completing education programmes. Although one study (King et al. 1982) was rated lower in quality, most studies showed that SLD individuals were more likely to need special education support and less likely to complete their education programmes (Aram et al. 1984; Armstrong et al. 2017; Durkin \& Conti-Ramsden 2007; Elbro et al. 2011; Howlin et al. 2000; Parsons et al. 2011; Whitehouse et al. 2009). More specifically, Johnson et al. (2010) reported lower educational attainment amongst young adults with a history of a language impairment when compared to those without impairments or early speech-only impairment. Although some studies reported reduced academic outcomes, students with an SLD tended to be satisfied with their academic results (Durkin et al. 2009); some were even more satisfied than their peers (Felsenfeld et al. 1994). One study found that participants with SLDs received 'acceptable' grades; however, this study lacked a control group for comparison and was a small sample (Brinton et al. 2010). Hall and Tomblin (1978) did not find consistent differences in academic outcomes between cases with a language disorder and articulation disorder controls. Similarly, King et al. (1982) reported no difference in academic achievement between groups with and without SLDs. Conti-Ramsden et al. and Durkin et al. also suggest that participants with a history of SLDs appear to have more opportunities now than in the 1990s (Conti-Ramsden et al. 2009; Durkin et al. 2009).

\section{Implications and recommendations}

This scoping review is the first comprehensive attempt to summarise the data available on the potential long-term effects of SLDs reported in the literature. These results have implications for individuals living with SLDs, their families and the clinicians advising them. Although the results varied, across the 51 studies that met the inclusion criteria, the most common results reported were suboptimal mental health, 
social well-being and academic outcomes for persons with a history of SLDs. Most studies $(n=40)$ reported mental health outcomes, while fewer studies $(n=17)$ explored academic outcomes. However, these findings are limited to only those reported by the authors in the studies reviewed. The average quality rating of the included studies did not seem to differ across these three domains. Studies published before 1990 were given lower quality ratings, predominantly because of the lack of reporting control groups and lower population representation in the samples. The differences in associations between SLDs and outcomes identified in the studies are likely a result of study-related factors, and therefore, clinical implications should be drawn based on study quality and applicability. Thirty-nine studies included more than 60 participants with SLDs, 41 included comparison groups, and 17 studies had a follow-up of 10 years or greater. Within the studies, different assessment tools were used to determine SLD, and terminology defining SLDs was non-uniform between studies. Because of the varied quality of the studies reviewed and the lack of terminology defining disorders, it was not possible to compare the severity of the SLDs described between studies; however, future reviews should seek to do so. Despite the international diagnostic variation, the evidence that childhood SLDs can have long-term impacts on mental health, social well-being and academic outcomes was strong.

\section{Long-term outcomes}

Having a childhood diagnosis of an SLD appears to be associated with mental health outcomes, with evidence most consistently indicating associations with personality disorders and behavioural problems. This is important for treating professionals to be aware of, as they are well positioned to refer patients to ancillary support services for early intervention. This review found a high association between SLDs and behavioural disorders; however, the authors were unclear whether this relationship was incidental or causative (Lindsay, Dockrell \& Strand 2007; Weinberg et al. 1998). It should be noted that other factors may have been responsible for these effects, including social, cognitive and genetic risk factors (Lau et al. 2007). Multilingual countries like South Africa face unique SLD diagnosis and treatment challenges (Jordaan \& Yelland 2003). More research aimed at these constructs will provide a better understanding of these problems in individuals with SLDs and how treating professionals can support them (Kathard \& Pillay 2013; Whitehouse et al. 2009). Additionally, studies reported the added difficulty of diagnosing SLDs in individuals with existing childhood behavioural or psychiatric disorders (Sundheim \& Voeller 2004). This phenomenon may have resulted in under- or overestimation of the occurrence of SLDs and therefore their impact within the studies. No association was found between childhood SLDs and substance use disorder. However, difficulties that are often comorbid with SLDs, such as self-regulation difficulties, hyperactivity and school-based difficulties, are seen to be potential precursors of substance use disorder (Weinberg et al. 1998).
Evidence for the impact of SLDs on relationships and employment varied. Evidence suggests that persons with a history of SLDs are more likely to be employed in unskilled or manual labour than their peers. In today's knowledge economy, which increasingly relies on knowledge over physical capital and labour (Brinkley 2006), workers who are unable to communicate clearly may be disadvantaged. This effect coupled with the decline in jobs in the manual sector and associated lower incomes may enhance the socioeconomic impacts of SLDs for individuals. This enhanced effect could potentially lead to exacerbation of their condition through reduced access to health services because of financial barriers (Ruben 2000). This could create a cycle of disadvantage and accentuate the impact of the social gradient on health from a young age (Law, Reilly \& Snow 2013), further disadvantaging vulnerable populations such as those with SLDs.

Similar to employment, evidence suggests that individuals with a history of SLDs are likely to experience overall lower academic achievement compared to their peers (King et al. 1982; Snowling et al. 2001). However, researchers also noted that individuals with SLDs may be as or more satisfied with their results than their peers (Felsenfeld et al. 1994; Records et al. 1992). These finding may reflect the fact that students with SLDs have to work harder than non-SLD peers for desired results and thus feel more satisfied with the academic outcomes they achieve (Records et al. 1992; Western \& Tomaszewski 2016). Regardless of the cause of this discrepancy, the finding that SLDs are associated with lower academic achievement has important implications for early diagnosis and intervention services.

\section{Clinical implications}

There is a consensus supporting diagnosis and intervention before formal schooling to improve SLD, and thus to avoid the child experiencing academic failure (Buschmann et al. 2009; Nippold 2012). Interventions that are frequent, intense and systematic, that promote engagement and attention of children within a supportive and positive environment, and that are tailored to focus on normal classroom language needs have been shown to facilitate positive outcomes for children with SLDs (Hartshorne 2009b; Nippold 2012). This evidence highlights the important role of speech pathologists in identifying and intervening early for children with SLD.

Earlier intervention could avert or reduce substantial and ongoing costs to the individual and society as a whole. Research from the UK reports that the annual benefit of speech pathology intervention for just three disorders (aphasia following stroke, SLD and autism) is $£ 765$ million (Royal College of Speech \& Language Therapists 2017). For example, 30 half-hour speechlanguage therapy sessions cost approximately $£ 671.00$ per patient, yet provide $£ 4455.00$ benefit per individual in terms of increased educational attainment and earnings (Royal College of Speech \& Language Therapists 2017). Research from the US and the UK reports significantly higher societal costs associated 
with individuals with SLDs. These costs are related to employment support, increased educational needs, welfare benefits, social service costs (resulting from behavioural and emotional development effects), mental health services, challenges communicating within the justice or health system and juvenile delinquency (Hartshorne 2009a; Speech Pathology Australia 2014). The healthcare and out-of-pocket costs for children with SLDs was higher in the age groups 4-5 years, 6-7 years and 10-11 years than for children without SLDs (Cronin et al. 2017). Therefore, appropriate early intervention by professionals such as speech pathologists could yield substantial economic and social cost savings, although further research needs to be conducted to quantify these savings.

\section{Limitations}

Differences in terminology, definitions and methods to assess outcomes across the included studies were a barrier for comparability and led to limitations within this review. In particular, many terms and different criteria were used to describe participants' SLDs, underlining the importance of the consistent terminology proposed by Bishop et al. (2016). As this review was intended to provide an overview of outcome effects, the results were not reported by disorder type. The studies reported results from individuals with different combinations and severity of SLDs, and this diversity presents difficulty in generalising the findings. Given the complex nature of SLDs, the exclusion of studies that reported SLDs resulting from biomedical conditions may have excluded relevant studies, as the interplay of biomedical and non-biomedical factors affecting SLDs is complex. However, this review provides an excellent collective representation of the effects of childhood SLDs in later life, which is relevant for developing health policy and fuelling advocacy. Additionally, studies were not excluded if they reported new results or results from different time points in the same data. While this has the potential to confound some of the results, as there was no meta-analysis of results it was not deemed inappropriate. Because of lack of terminology within the literature, some eligible studies may not have been captured during the initial searches; however, all search terms, inclusion and exclusion criteria and methods have been outlined clearly to improve reproducibility. The studies included spanned a large range of ages because of variations in their enrolment ages and follow-up periods. This variation may affect the generalisability of results to all age groups; however, this is why the scoping review method was used. Additionally, as the literature searches were conducted in 2017 and the analysis and synthesis of results took an extended period, future research could examine more recent literature and use this review as a foundation.

In this scoping review, a quality assessment tool was used to group studies and potentially explain diverging findings, increasing the quality of the investigation. Despite receiving criticism for rating validity and inter-rater reliability (Hartling et al. 2013; Lo, Mertz \& Loeb 2014), the Newcastle-Ottawa scale has been used extensively (Abdel-Latif et al. 2007; Aziz et al. 2006; Margulis et al. 2014; Prins \& Van der Wurff 2009). It has also been endorsed by the Cochrane Collaboration for use in assessing the study quality of observational studies and has been reported as a convenient and adaptable tool (Margulis et al. 2014). To minimise these potential shortcomings, two researchers independently rated the quality of each eligible study, with the third researcher adjudicating the differences until consensus was reached.

\section{Conclusion}

This review of 51 cohort studies provides evidence that individuals who have childhood SLDs may experience a higher incidence of mental health difficulties, reduced social well-being and reduced academic achievement compared to their peers. The results also indicate that childhood SLDs are complex, and their effects can persist into adolescence and adulthood, potentially causing significant negative effects for the individual, society and the healthcare system, supporting the importance of early intervention and improvements in access. Further research examining the long-term effects of childhood SLDs is required to conclusively determine the impact of SLDs on each of these domains.

\section{Acknowledgements}

The authors thank Monica Taylor and Maike Neuhaus for their assistance with the article review.

\section{Competing interests}

The authors declare that they have no financial or personal relationships that may have inappropriately influenced them in writing this review article.

\section{Authors' contribution}

All authors contributed equally to this work.

\section{Ethical consideration}

This article followed all ethical standards for research without direct contact with human or animal subjects.

\section{Funding information}

This review was conducted with the support of the Centre of Research Excellence in Telehealth funded by the National Health and Medical Research Council (NHMRC;APP1061183), and the Health-e-Regions project, which supports the delivery of telehealth services throughout the Western Downs region in Queensland, funded by QGC Pty Ltd.

\section{Data availability statement}

Data sharing is not applicable to this article, as no new data were created or analysed in this study.

\section{Disclaimer}

The contents of the published material are solely the responsibility of the individual authors and do not reflect the views of NHMRC or other funding agencies. 


\section{References}

Abdel-Latif, A., Bolli, R., Tleyjeh, I.M., Montori, V.M., Perin, E.C., Hornung, C.A. et al., 2007, 'Adult bone marrow-derived cells for cardiac repair: A systematic review and meta-analysis', Archives of Internal Medicine 167(10), 989-997. https://doi. org/10.1001/archinte.167.10.989

Aram, D.M., Ekelman, B.L. \& Nation, J.E., 1984, 'Preschoolers with language disorders 10 years later', Journal of Speech, Language, and Hearing Research 27(2), 232-244. https://doi.org/10.1044/jshr.2702.244

Arkkila, E., Räsänen, P., Roine, R. \& Vilkman, E., 2008, 'Specific language impairment in childhood is associated with impaired mental and social well-being in adulthood', Logopedics Phoniatrics Vocology 33(4), 179-189. https://doi.org/10.1080/ 14015430802088289

Arkkila, E., Räsänen, P., Roine, R.P., Sintonen, H., Saar, V. \& Vilkman, E., 2009, 'Healthrelated quality of life of adolescents with childhood diagnosis of specific language impairment', International Journal of Pediatric Otorhinolaryngology 73(9), 1288-1296. https://doi.org/10.1016/j.ijporl.2009.05.023

Armstrong, R., Arnott, W., Copland, D.A., McMahon, K., Khan, A., Najman, J.M. et al., 2017, 'Change in receptive vocabulary from childhood to adulthood: Associated mental health, education and employment outcomes', International Journal of Language \& Communication Disorders 52(5), 561-572. https://doi.org/ 10.1111/1460-6984.12301

Aziz, O., Constantinides, V., Tekkis, P. P., Athanasiou, T., Purkayastha, S., Paraskeva, P. et al., 2006, 'Laparoscopic versus open surgery for rectal cancer: A meta-analysis', Annals of Surgical Oncology 13, 413-424. https://doi.org/10.1245/ASO.2006.05.045

Baker, L. \& Cantwell, D.P., 1987, 'A prospective psychiatric follow-up of children with speech/language disorders', Journal of the American Academy of Child \& Adolescent Psychiatry 26(4), 546-553. https://doi.org/10.1097/00004583198707000-00015

Baltaxe, C.A. \& Simmons, J.Q., 3rd., 1975, 'Language in childhood psychosis: A review' Journal of Speech and Hearing Disorders 40(4), 439-458. https://doi.org/10.1044/ jshd.4004.439

Beitchman, J.H., Brownlie, E.B. \& Bao, L., 2014, 'Age 31 mental health outcomes of childhood language and speech disorders', Journal of American Academy of Child \& Adolescent Psychiatry 53(10), 1102-1110 e8. https://doi.org/10.1016/j. \& Adolescent Psych

Beitchman, J.H., Brownlie, E.B., Inglis, A., Wild, J., Ferguson, B., Schachter, D. et al., 1996, 'Seven-year follow-up of speech/language impaired and control children: Psychiatric outcome', Journal of Child Psychology and Psychiatry and Allied Psychiatric outcome', Journal of Child Psychology and Psychiatry and Allied
Disciplines 37(8), 961-970. https://doi.org/10.1111/j.1469-7610.1996.tb01493.x

Beitchman, J.H., Douglas, L., Wilson, B., Johnson, C., Young, A., Atkinson, L. et al., 1999, 'Adolescent substance use disorders: Findings from a 14-year follow-up of speech/language/impaired and control children' Journal of Clinical Child speech/language/impaired and control children', Journal of Clinical
Psychology 28(3), 312-321. https://doi.org/10.1207/S15374424jccp280303

Beitchman, J.H., Wilson, B., Brownlie, E.B., Walters, H., Inglis, A. \& Lancee, W., 1996, 'Long-term consistency in speech/language profiles: II. Behavioral, emotional, and social outcomes', Journal of the American Academy of Child \& Adolescent Psychiatry 35(6), 815-825. https://doi.org/10.1097/00004583-199606000-00022

Beitchman, J. H., Wilson, B., Johnson, C.J., Atkinson, L., Young, A., Adlaf, E. et al., 2001, 'Fourteen-year follow-up of speech/language-impaired and control children: Psychiatric outcome', Journal of the American Academy of Child \& Adolescent Psychiatry 40(1), 75-82. https://doi.org/10.1097/00004583-200101000-00019

Benasich, A.A., Curtiss, S. \& Tallal, P., 1993, 'Language, learning, and behavioral disturbances in childhood: A longitudinal perspective', Journal of American Academy of Child \& Adolescent Psychiatry 32(3), 585-594. https://doi. org/10.1097/00004583-199305000-00015

Bishop, D.V., Snowling, M.J., Thompson, P.A., Greenhalgh, T. \& Consortium, C., 2016 'CATALISE: A multinational and multidisciplinary delphi consensus study. Identifying language impairments in children', PLoS One 11(12), e0158753. https://doi.org/10.1371/journal.pone.0158753

Black, L.I., Vahratian, A. \& Hoffman, H.J., 2015, Communication disorders and use of intervention services among children aged 3-17 years: United States, 2012, US Department of Health and Human Services, Centers for Disease Control and Prevention, National Center for Health Statistics, Atlanta, GA, USA.

Botting, N. \& Conti-Ramsden, G., 2008, 'The role of language, social cognition, and social skill in the functional social outcomes of young adolescents with and without a history of SLI', British Journal of Developmental Psychology 26(2), 281-300. https://doi.org/10.1348/026151007X235891

Brinkley, I., 2006, Defining the knowledge economy. Knowledge economy program report, The Work Foundation, London.

Brinton, B., Fujiki, M. \& Baldridge, M., 2010, 'The trajectory of language impairment into adolescence: What four young women can teach us', Seminars in Speech and Language, Thieme 31(2), 122-133. https://doi.org/10.1055/s-0030-1252113

Brownlie, E.B., Beitchman, J.H., Escobar, M., Young, A., Atkinson, L., Johnson, C. et al., 2004, 'Early language impairment and young adult delinquent and aggressive behavior', Journal of Abnormol Child Psychology 32, 453-467. https://doi. org/10.1023/B:JACP.0000030297.91759.74

Brownlie, E.B., Jabbar, A., Beitchman, J., Vida, R. \& Atkinson, L., 2007, 'Language impairment and sexual assault of girls and women: Findings from a community sample', Journal of Abnormol Child Psychology 35, 618-626. https://doi. org/10.1007/s10802-007-9117-4

Buschmann, A., Jooss, B., Rupp, A., Feldhusen, F., Pietz, J. \& Philippi, H., 2009, 'Parent based language intervention for 2-year-old children with specific expressive language delay: A randomised controlled trial', Archives of Disease in Childhood 94(2), 110-116. https://doi.org/10.1136/adc.2008.141572
Clegg, J., 2006, 'Childhood speech and language difficulties and later life chances', in J. Clegg \& J. Ginsborg (eds.), Language and social disadvantage: Theory into practice, pp. 59-73, John Wiley, Chichester.

Clegg, J., Hollis, C., Mawhood, L. \& Rutter, M., 2005, 'Developmental language disorders-a follow-up in later adult life. Cognitive, language and psychosocial outcomes', Journal of Child Psychology and Psychiatry 46(2), 128-149. https://doi. org/10.1111/j.1469-7610.2004.00342.x

Community Affairs References Committee \& Siewert, R., 2014, Prevalence of different types of speech, language and communication disorders and speech pathology services in Australia, ACT: Community Affairs References Committee, Canberra.

Conti-Ramsden, G. \& Botting, N., 2008, 'Emotional health in adolescents with and without a history of specific language impairment (SLI)', Journal of Child Psychology and Psychiatry 49(5), 516-525. https://doi.org/10.1111/j.14697610.2007.01858.x

Conti-Ramsden, G. \& Durkin, K., 2008, 'Language and independence in adolescents with and without a history of specific language impairment (SLI)', Journal of speech Language and Hearing Research 51(1), 70-83. https://doi. org/10.1044/1092-4388(2008/005)

Conti-Ramsden, G., Durkin, K., Simkin, Z. \& Knox, E., 2009, 'Specific language impairment and school outcomes. I: Identifying and explaining variability at the end of compulsory education', International Journal of Language \& Communication Disorders 44(1), 15-35. https://doi.org/10.1080/13682820801921601

Cronin, P., Reeve, R., Mccabe, P., Viney, R. \& Goodall, S., 2017, 'The impact of childhood language difficulties on healthcare costs from 4 to 13 years: Australian longitudinal study', Internatinal Journal of Speech and Language Pathology 19(4), 381-391. https://doi.org/10.1080/17549507.2016.1216599

Durkin, K. \& Conti-Ramsden, G., 2007, 'Language, social behavior, and the quality of friendships in adolescents with and without a history of specific language impairment', Child Development 78(5), 1441-1457. https://doi.org/ 10.1111/j.1467-8624.2007.01076.x

Durkin, K., Conti-Ramsden, G. \& Simkin, Z., 2012, 'Functional outcomes of adolescents with a history of specific language impairment (SLI) with and without autistic
symptomatology', Journal of Autism and Developmental Disorders 42, 123-138. symptomatology', Journal of Autism and De
https://doi.org/10.1007/s10803-011-1224-y

Durkin, K., Simkin, Z., Knox, E. \& Conti-Ramsden, G., 2009, 'Specific language impairment and school outcomes. II: Educational context, student satisfaction, and post-compulsory progress', International Journal of Language \& and post-compulsory progress', International Journal of Language \&
Communication Disorders 44(1), 36-55. https://doi.org/10.1080/ Communication Dis

Efstratiadou, E.A., Papathanasiou, I., Holland, R., Archonti, A. \& Hilari, K., 2018, 'A systematic review of semantic feature analysis therapy studies for aphasia', systematic review of semantic feature analysis therapy studies for aphasia',
Journal of Speech, Language, and Hearing Research 61(5), 1261-1278. https:// Journal of Speech, Language, and Hearing
doi.org/10.1044/2018 JSLHR-L-16-0330

Elbro, C., Dalby, M. \& Maarbjerg, S., 2011, 'Language-learning impairments: A 30-year follow-up of language-impaired children with and without psychiatric, neurological and cognitive difficulties', International Journal of Language \& Communication Disorders 46(4), 437-448. https://doi.org/10.1111/j.1460-6984.2011.00004.x

Felsenfeld, S., Broen, P.A. \& McGue, M., 1992, 'A 28-year follow-up of adults with a history of moderate phonological disorder: Linguistic and personality results', Jorunal of Speech and Hearing Research 35(5), 1114-1125. https://doi. org/10.1044/jshr.3505.1114

Felsenfeld, S., Broen, P.A. \& McGue, M., 1994, 'A 28-year follow-up of adults with a history of moderate phonological disorder: Educational and occupational results', Journal of Speech and Hearing Research 37(6), 1341-1353. https://doi. org/10.1044/jshr.3706.1341

Glogowska, M., Roulstone, S., Peters, T.J. \& Enderby, P., 2006, 'Early speech- and language-impaired children: Linguistic, literacy, and social outcomes', Developmental Medicine and Child Neurology 48, 489-494. https://doi. org/10.1111/j.1469-8749.2006.tb01301.x

Gross, J., 2006, The long term costs of literacy difficulties, KPMG Foundation, London.

Grudniewicz, A., Nelson, M., Kuluski, K., Lui, V., Cunningham, H.V., Jason, X.N. et al., 2016, 'Treatment goal setting for complex patients: Protocol for a scoping review', BMJ Open 6(5), e011869. https://doi.org/10.1136/bmjopen-2016-011869

Hall, P.K. \& Tomblin, J.B., 1978, 'A follow-up study of children with articulation and language disorders', Journal of Speech and Hearing Disordors 43(2), 227-241. language disorders', Journal of Speech
https://doi.org/10.1044/jshd.4302.227

Hartling, L., Milne, A., Hamm, M.P., Vandermeer, B., Ansari, M., Tsertsvadze, A. et al., 2013, 'Testing the Newcastle Ottawa Scale showed low reliability between individual reviewers', Journal of Clinical Epidemiology 66, 982-993. https://doi. org/10.1016/j.jclinepi.2013.03.003

Hartshorne, M., 2009a, The cost to the nation of childrens poor communication London I CAN.

Hartshorne, M., 2009b, Speech, language and communication needs and literacy difficulties, I CAN, London.

Howlin, P., Mawhood, L. \& Rutter, M., 2000, 'Autism and developmental receptive language disorder - A follow-up comparison in early adult life. II: Social, behavioural, and psychiatric outcomes', Journal of Child Psychology and Psychiatry 41(5), 561-578. https://doi.org/10.1111/1469-7610.00643

Jackson, S., Pretti-Frontczak, K., Harjusola-Webb, S., Grisham-Brown, J. \& Romani, J.M., 2009, 'Response to intervention: Implications for early childhood professionals', Language, Speech, and Hearing Services in School 40(4), 424-434. https://doi.org/10.1044/0161-1461(2009/08-0027)

Johnson, C.J., Beitchman, J.H. \& Brownlie, E.B., 2010, 'Twenty-year follow-up of children with and without speech-language impairments: Family, educational, Pathology 19(1), 51-65. https://doi.org/10.1044/1058-0360(2009/08-0083) 
Jordaan, H. \& Yelland, A., 2003, 'Intervention with multilingual language impaired children by South African speech-language therapists', Journal of Multilingual Communication Disorders 1(1), 13-33. https://doi.org/10.1080/14769 67031000102959

Kathard, H. \& Pillay, M., 2013, 'Promoting change through political consciousness: A South African speech-language pathology response to the world report on disability', International Journal of Speech-Language Pathology 15(1), 84-89. https://doi.org/10.3109/17549507.2012.757803

Kent, R.D. \& Vorperian, H.K., 2013, 'Speech impairment in down syndrome: A review', Journal of Speech, Language, and Hearing Research 56, 178-210. https://doi. org/10.1044/1092-4388(2012/12-0148)

King, R.R., Jones, C. \& Lasky, E., 1982, 'In retrospect a fifteen-year follow-up report of speech-language-disordered children', Language, Speech, and Hearing Services in Schools 13(1), 24-32. https://doi.org/10.1044/0161-1461.1301.24

Lau, J.Y., Rijsdijk, F., Gregory, A.M., McGuffin, P. \& Eley, T.C., 2007, 'Pathways to childhood depressive symptoms: The role of social, cognitive, and genetic risk factors', Devepmental Psychology 43(6), 1402-1414. https://doi.org/10.1037/ 0012-1649.43.6.1402

aw, J., Boyle, J., Harris, F., Harkness, A. \& Nye, C., 2000, 'Prevalence and natural history of primary speech and language delay: Findings from a systematic review of the literature', International Journal of Language and Communication Disorders of the literature', International Journal of Language and Comm
35(2):165-88. https://doi.org/10.1080/136828200247133.

Law, J., Levickis, P., Mckean, C., Goldfeld, S., Snow, P. \& Reilly, S., 2017, Child language in a public health context: Synthesising research evidence to inform policy,
Murdoch Childrens Research Institute, Melbourne. https://doi.org/10.13140/ Murdoch Childrens

Law, J., Reilly, S. \& Snow, P.C., 2013, 'Child speech, language and communication need re-examined in a public health context: A new direction for the speech and language therapy profession', International Journal of Language \& Communication Disordors 48(5), 486-496. https://doi.org/10.1111/1460 6984.12027

Law, J., Rush, R., Schoon, I. \& Parsons, S., 2009, 'Modeling developmental language difficulties from school entry into adulthood: Literacy, mental health, and employment outcomes', Journal of Speech, Language, and Hearing Research 52(6), 1401-1416. https://doi.org/10.1044/1092-4388(2009/08-0142)

Levac, D., Colquhoun, H. \& O'Brien, K.K., 2010, 'Scoping studies: Advancing the methodology', Implementation Science 5, 1. https://doi.org/10.1186/1748-59085-69

Lewis, B.A., Patton, E., Freebairn, L., Tag, J., Iyengar, S.K., Stein, C.M. et al., 2016, 'Psychosocial co-morbidities in adolescents and adults with histories of communication disorders', Journal of Communication Disorders 61, 60-70. https://doi.org/10.1016/j.jcomdis.2016.03.004

Lindsay, G., DockrellI, J. \& Palikara, O, 2010, 'Self-esteem of adolescents with specific language impairment as they move from compulsory education', International Journal of Language \& Communication Disorders 45(5), 561-571. https://doi. org/10.3109/13682820903324910

Lindsay, G., Dockrell, J.E. \& Strand, S., 2007, 'Longitudinal patterns of behaviour problems in children with specific speech and language difficulties: Child and contextual factors', The British Journal of Educational Psychology 77(4), 811-828. https://doi.org/10.1348/000709906X171127

Lo, C.K., Mertz, D. \& Loeb, M., 2014, 'Newcastle-Ottawa Scale: Comparing reviewers' to authors' assessments', BMC Medical Research Methodology 14, 45. https://doi. org/10.1186/1471-2288-14-45

Maggi, S., Irwin, L.J., Siddiqi, A. \& Hertzman, C., 2010, 'The social determinants of early child development: An overview', Journal of Paediatrics and Child Health 46(11):627-35. https://doi.org/10.1111/j.1440-1754.2010.01817.x.

Margulis, A.V., Pladevall, M., Riera-Guardia, N., Varas-Lorenzo, C., Hazell, L., Berkman, N.D. et al., 2014, 'Quality assessment of observational studies in a drug-safety systematic review, comparison of two tools: The Newcastle-Ottawa Scale and the RTI item bank', Clinical Epidemiology 6, 359. https://doi.org/10.2147/CLEP.S66677

Mccormack, J., McLeod, S., McAllister, L. \& Harrison, L.J., 2007, 'Prevalence of communication impairment in Australian children', Poster Presented at American Speech-Language-Hearing Association Convention, Boston, MA, November 2014 14-17, 2007.

Mouridsen, S.E. \& Hauschild, K.M., 2009a, 'A long-term study of offending in individuals diagnosed with a developmental language disorder as children', International Journal of Speech-Language Pathology 11(3), 171-179. https://doi. org/10.1080/17549500802579095

Mouridsen, S.E. \& Hauschild, K.M., 2009b, 'A longitudinal study of personality disorders in individuals with and without a history of developmental language disorder', Logopedics Phoniatrics Vocology 34(3), 135-141. https://doi. org/10.1080/14015430903117441

Mouridsen, S.E. \& Hauschild, K.M., 2010, 'Substance use disorders: Findings from a longitudinal study of individuals with and without a history of developmental language disorders', Folia Phoniatrica et Logopaedica 63, 195-200. https://doi. org/10.1159/000316413

Nippold, M.A., 2012, 'Different service delivery models for different communication disorders', Lanquage, Speech, and Hearing Services in Schools 43(2), 117-120. https://doi.org/10.1044/0161-1461(2012/ed-02)
Nwosu, N., 2015, 'Systemic review of the prevalence of speech and language disorders in Nigeria', International Journal of Humanities and Social Science 5(5), 130-133.

Parsons, S., Schoon, I., Rush, R. \& Law, J., 2011, 'Long-term outcomes for children with early language problems: Beating the odds', Children \& Society 25(3), 202-214. https://doi.org/10.1111/j.1099-0860.2009.00274.x

Pascoe, M., Mahura, O. \& Le Roux, J., 2018, 'South African english speech development: Preliminary data from typically developing preschool children in Cape Town', Clinical Linguistics \& Phonetics 32(12), 1145-1161. https://doi.org/ 10.1080/02699206.2018.1510985

Prins, M.R. \& Van Der Wurff, P., 2009, 'Females with patellofemoral pain syndrome have weak hip muscles: A systematic review', Australian Journal of Physiotherapy 55(1), 9-15. https://doi.org/10.1016/S0004-9514(09)70055-8

Records, N.L., Tomblin, J.B. \& Freese, P.R., 1992, 'The quality of life of young adults with histories of specific language impairment', American Journal of SpeechLanguage Pathology 1, 44-53. https://doi.org/10.1044/1058-0360.0102.44

Royal College of Speech \& Language Therapists, 2017, Cost benefit analysis models for SLTs, London Royal College of Speech \& Language Therapists, viewed 14 August 2017, from https://www.rcsit.org/speech_and_language_therapy/commissioning/ cost_benefit_analysis_models.

Ruben, R.J., 2000, 'Redefining the survival of the fittest: Communication disorders in the 21st century', Laryngoscope 110(2), 241-245. https://doi. org/10.1097/00005537-200002010-00010

Schoon, I., Parsons, S., Rush, R. \& Law, J., 2010, 'Children's language ability and psychosocial development: A 29-year follow-up study', Pediatrics 126(1), e73-e80. https://doi.org/10.1542/peds.2009-3282

Snowling, M.J., Adams, J.W., Bishop, D.V.M. \& Stothard, S.E., 2001, 'Educational attainments of school leavers with a preschool history of speech-language impairments', International Journal of Language \& Communication Disorders 36(2), 173-183. https://doi.org/10.1080/13682820010019892

Snowling, M.J., Bishop, D.V.M., Stothard, S.E., Chipchase, B. \& Kaplan, C., 2006 'Psychosocial outcomes at 15 years of children with a preschool history of speech-
language impairment', Journal of Child Psychology and Psychiatry 47(8), 759-765. language impairment', Journal of Child Psychology a
https://doi.org/10.1111/j.1469-7610.2006.01631.x

Speech Pathology Australia, 2014, 'Prevalence of different types of speech, language and communication disorders and speech pathology services in Australia', Submission to the Inquiry into the Prevalence of Different Types of Speech, Language and Communication Disorders and Speech Pathology Services in Australia; Senate and Communication Disorders and Speech Pathology Services in Australia; Senate
Community Affairs Reference Committee, Melbourne Speech Pathology Australia, Community Affairs Reference Committee, Melbourne
Commonwealth of Australia 2014, Canberra, Australia,

St Clair, M.C., Pickles, A., Durkin, K. \& Conti-Ramsden, G., 2011, 'A longitudinal study of behavioral, emotional and social difficulties in individuals with a history of 186-199. https://doi.org/10.1016/j.jcomdis.2010.09.004

Stattin, H. \& Klackenberglarsson, I., 1993, 'Early language and intelligence development and their relationship to future criminal behavior', Journal of Abnormal Psychology 102(2), 369-378. https://doi.org/10.1037/0021-843X.102.3.369

Sundheim, S.T. \& Voeller, K.K., 2004, 'Psychiatric implications of language disorders and learning disabilities: Risks and management', Journal of Child Neurology 19(10), 814-826. https://doi.org/10.1177/08830738040190101001

Wadman, R., Botting, N., Durkin, K. \& Conti-Ramsden, G., 2011a, 'Changes in emotional health symptoms in adolescents with specific language impairment', International Journal of Language \& Communication Disorders 46(6), 641-656. International Journal of Language \& Communication
https://doi.org/10.1111/j.1460-6984.2011.00033.x

Wadman, R., Durkin, K. \& Conti-Ramsden, G., 2011b, 'Close relationships in adolescents with and without a history of specific language impairment', Language, Speech, and Hearing Services in Schools 42(1), 41-51. https://doi. org/10.1044/0161-1461(2010/10-0003)

Weinberg, N.Z., Rahdert, E., Colliver, J.D. \& Glantz, M.D., 1998, 'Adolescent substance abuse: A review of the past 10 years', Journal of the American Academy of Child \& Adolescent Psychiatry 37(3), 252-261. https://doi.org/10.1097/00004583199803000-00009

Wells, G., Shea, B., O'connell, D., Peterson, J., Welch, V., Losos, M. et al., 2000, The Newcastle-Ottawa Scale (NOS) for assessing the quality of nonrandomised studies in meta-analyses, Department of Epidemiology and Community Medicine, University of Ottawa, Ottawa, Canada.

Western, M. \& Tomaszewski, W., 2016, 'Subjective wellbeing, objective wellbeing and inequality in Australia', PLOS One 11(10), e0163345. https://doi.org/10.1371/ journal.pone.0163345

Whitehouse, A.J., Robinson, M. \& Zubrick, S.R., 2011, 'Late talking and the risk for psychosocial problems during childhood and adolescence', Pediatrics 128(2) e324-e332. https://doi.org/10.1542/peds.2010-2782

Whitehouse, A.J., Watt, H.J., Line, E. \& Bishop, D.V., 2009, 'Adult psychosocia outcomes of children with specific language impairment, pragmatic language impairment and autism', International Journal of Language \& Communication Disorders 44(4), 511-528. https://doi.org/10.1080/ 13682820802708098

Yew, S.G.K. \& O'kearney, R., 2015, 'Early language impairments and developmental pathways of emotional problems across childhood', International Journal of Language \& Communication Disorders 50(3), 358-373. https://doi.org/10. $1111 / 1460-6984.12142$ 


\section{Appendix 1}

TABLE 1-A1: Modified Newcastle-Ottawa scale for assessing the quality of included studies.

\begin{tabular}{|c|c|c|}
\hline Domain & Indicator and item & Scoring \\
\hline \multirow[t]{9}{*}{ Selection bias } & Representativeness in the intervention cohort: & \\
\hline & $\begin{array}{l}\text { Truly or somewhat representative of the average } \\
\text { speech and language-impaired child in the } \\
\text { community }\end{array}$ & 1 \\
\hline & $\begin{array}{l}\text { - Selected group of participants or no description } \\
\text { of the derivation of the cohort }\end{array}$ & 0 \\
\hline & Selection of non-impaired cohort: & \\
\hline & $\begin{array}{l}\text { - Drawn from the same community as the } \\
\text { impaired cohort }\end{array}$ & 1 \\
\hline & $\begin{array}{l}\text { Drawn from a different source or no description } \\
\text { of the derivation of the non-impaired cohort }\end{array}$ & 0 \\
\hline & Ascertainment of impairment: & \\
\hline & $\begin{array}{l}\text { Diagnosed by speech and language pathologist } \\
\text { or validated assessment by researcher }\end{array}$ & 1 \\
\hline & - Self-report, other or no description & 0 \\
\hline \multirow[t]{3}{*}{ Comparability } & $\begin{array}{l}\text { Comparability of cohorts on the basis of the design or } \\
\text { analysis: }\end{array}$ & \\
\hline & $\begin{array}{l}\text { - Study controls for one of the following factors: } \\
\text { socio-economic status, maternal education, } \\
\text { literacy and language, gender and non-verbal IQ }\end{array}$ & 1 \\
\hline & $\begin{array}{l}\text { - Study controls for more than one or any } \\
\text { additional factors }\end{array}$ & 1 \\
\hline \multirow[t]{9}{*}{ Outcome } & Assessment of outcome: & \\
\hline & $\begin{array}{l}\text { - Assessment by validated instruments, semi- } \\
\text { structured interviews or record linkage }\end{array}$ & 1 \\
\hline & - Self-report, other or no description & 0 \\
\hline & Adequacy of follow-up period: & \\
\hline & - Follow-up period, $10+$ years & 1 \\
\hline & - Follow-up period, $<10$ years & 0 \\
\hline & Adequacy of follow-up of cohorts: & \\
\hline & $\begin{array}{l}\leq 30 \% \text { of participants lost to follow-up or } \\
\text { description of those lost suggesting no difference } \\
\text { from those followed }\end{array}$ & 1 \\
\hline & $\begin{array}{l}-<30 \% \text { of participants lost to follow-up, } \\
\text { description of those lost suggesting difference } \\
\text { from those followed, or no information }\end{array}$ & 0 \\
\hline
\end{tabular}

$\mathrm{IQ}$, intelligence quotient. 